\title{
Effectiveness of Learning Tool Basic Dance South Sulawesi (Mandar) Sendratasik Education Study Program Faculty of Arts and Design Makassar State University
}

\author{
Andi Padalia ${ }^{1}$, Sofyan Salam ${ }^{1}$, Amir $^{1} \&$ Nurdin Arsyad ${ }^{1}$ \\ ${ }^{1}$ Makassar State University, Indonesia \\ Correspondence: Andi Padalia, Makassar State University, Indonesia. E-mail: fsdunm_padalia@yahoo.com
}

Received: April 17, 2015 Accepted: May 26, 2015 Online Published: September 28, 2015

doi:10.5539/ies.v8n10p207 URL: http://dx.doi.org/10.5539/ies.v8n10p207

\begin{abstract}
Objective research to determine the effectiveness of the learning device Basic Dance South Sulawesi (Mandar) on Sendratasik Education Program Faculty of Arts and Design University of Makassar. This type of research is the Research and Development (R \& D). The object of research includes learning tools Basic Dance South Sulawesi (Mandar) in the form of textbook for students and instructional videos that have been developed. Data were collected by the students' test results and questionnaire. Data were then analyzed using descriptive statistics. The results showed that roughly devices that have been developed have met the criteria of effectiveness. However, the test results are still learning tools necessary to hold further revised in relation with the advice and input of validators as well as observers and students. In order to obtain the basic learning dance cooperative model based Sulawesi valid, effective, and practical.
\end{abstract}

Keywords: textbook, video learning, cooperative learning

\section{Introduction}

Creative learning process, interactive, innovative are the main objective of the teachers to improve the ability to membelajarkan students so that the learning process can be accomplished, to support effective learning the necessary learning tools. Trianto (2009) suggests that "learning devices are a number of materials, tools, learning tools needed to manage the learning process such as: syllabus, lesson plans, student activity sheets, instruments or tests Learning Outcomes evaluation, instructional media, and student textbook". In this study the effectiveness of learning to be observed is the textbook for students and instructional videos that have been developed using the model of instructional development 4-D, which consists of four (4) stages of development, namely Define, Design, Develop, and Desseminate or adapted into Model 4-P, ie Defining, Designing, Development, and Deployment (Thiagarajan, 1974).

Textbook is a book that is used as a handle by learners or students as learning materials related to the field of study (Departament National Education, 2006). While the instructional video is a type of media that is able to show moving images integrated with sound elements. This media type has the features or exceptional ability as a medium of communication (Heinich, 1996).

The process of learning in Arts Education Studies Program in high school level is very different from other education that emphasizes the mastery of dance based on the origin of the dance, while at the college level is based on the type of courses that develop specific knowledge and mastery dance deeper objective. This is reflected in the curriculum structure at Arts Education Studies Program, Makassar State University. In this study used a model of cooperative learning. Slavin (1987) and Slage (2009) defines that cooperative learning is a strategy that consists of cooperation between students in small groups divided by heterogeneous to achieve a particular goal. Characteristics of cooperative learning is characterized by the presence of three (3) the structure of the structure of the task, the structure of goals, and reward structures (Ibrahim, 2005).

Observations were conducted by researchers in the field data showed that the basic learning outcomes dance of South Sulawesi which consists of four ethnic incompatible with the purpose of learning due time to dance basic subjects South Sulawesi only 2 (two) Semester Credit System (SCS), with code H12C212 courses, while learning material includes four ethnic dances, namely ethnic Bugis, Makassar, Mandar and Toraja. Among the four subjects of the research will focus on one subject that is learning basic dance ethnic Mandar South Sulawesi 
where chosen as the basic dance is dance Pattukduk Kumba.

One subject of learning basic dance of South Sulawesi, where researchers focused choose Mandar basic dance (dance Pattukduk Kumba) because previous research on the dance Pattukduk Kumba only discuss the shift in the orientation of the value of the sacred to profane (Padalia, 2002). Other research conducted by Ram (2000). Dancing the Past Into Life: The Flavor, Nirtia and Sports of Immigrant Existence, which illustrates that the reason the orientation towards cultural values as a representation of a human civilization is a fundamental disturbance in the relationship main to the past and the present, the script turned into Indian dance and music is a good language for representation and appreciate the magical powers diligence of the level of experience that is manifested in a coherent and meaningful without having any depiction.

Based on the above learning Dance Basics South Sulawesi (Ethnic Mandar) which has been applied to the study program Sendratasik the number of students is quite large (35-40 people), to measure subjects considered ineffective practices that need to be innovative efforts as solutions to solve their problems. So the research issue is the effectiveness of the learning device Basic Dance South Sulawesi ethnic Mandar in Arts Education Studies Program at Makassar State University.

\section{Research Methods}

This type of research is the Research and Development (R \& D) is a study that intends to produce certain products and also test the practicality and effectiveness of these products. The focus of this research is the implementation of learning tools Basic Dance South Sulawesi (Ethnic Mandar) based cooperative. The subjects were textbook for students and instructional videos that used in Study Program Sendratsik Makassar State University in the academic year 2011/2012.

Data were collected through test and questionnaire. Moreover, the instrument used to collect data is the knowledge test and a questionnaire (questionnaire). Knowledge tests are given to students to determine the extent of their understanding of the course Basic Dance South Sulawesi (Ethnic Mandar), and determine the effectiveness of the implementation textbook for students and instructional videos. Questionnaires are given to the students to study the response of students to study Dance Association of South Sulawesi (Ethnic Mandar). The data collected in this study a quantitative data were analyzed using descriptive statistics.

Assessment of the learning is done with reference to the quality criteria proposed curriculum Nieveen (1999), namely: (1) the validity; (2) practicality; and (3) effectiveness. On the basis of the opinion of the Nieveen, then the Basic Dance South Sulawesi (Mandar) developed in this study said if the quality meets the criteria, namely:

- The opinion of experts and practitioners, theoretically that the learning device can be accomplished with good and declared invalid;

- A device developed can be done well in the field by using the indicator device feasibility study, the ability of faculty to manage learning, and student activities that otherwise impractical to use; and

- The implementation of learning tools provide optimal results for the purpose of learning to use the indicator test mastery of learning outcomes and student response to learning.

\section{Results and Discussion}

Based on the analysis of data collected, it is known that the organization of the course Basic Dance South Sulawesi (Ethnic Mandar) using learning tools such as textbooks for students and instructional videos can be explained as follows:

\section{Textbook for Students}

Textbook for students is designed to assist students in independent study (without the presence of a lecturer) either individually or in groups. Textbook for students is based on the syllabus and Semester Lesson Plan. Textbooks are made to complement the learning device components subject Dance of South Sulawesi and are expected to assist students in following and completing the lecture as well as the expected objectives can be achieved with the maximum tuition.

Textbook for students is one component of the learning device designed and prepared based on the semester syllabus and lesson plans were developed. This textbook contains material Basic course South Sulawesi Dance "Pattukduk" ethnic Mandar. Textbooks are made to complement the learning device components subject Dance Association of South Sulawesi and are expected to help lecturers and students in implementing and completing the subject as well as the expected objectives can be achieved with the maximum expectation. Fill textbook for students can be seen in Figure 1 below. In addition to the systematic of the book above, the textbook for students is also equipped with an evaluation sheet. 


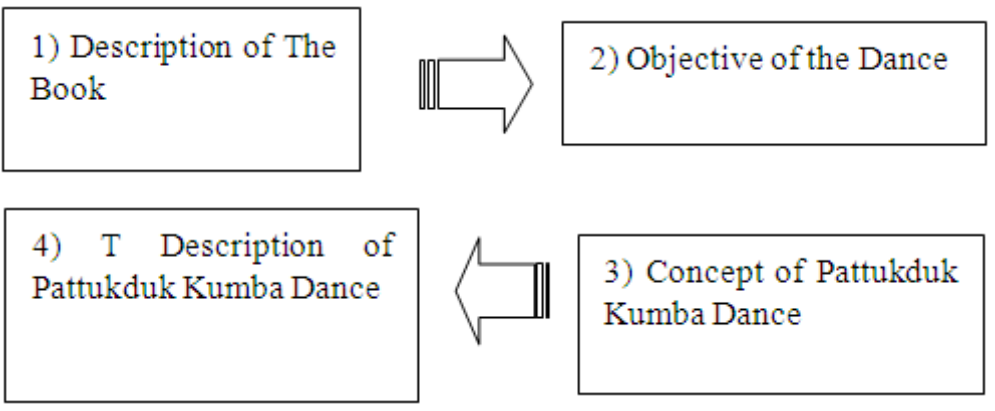

Figure 1. Structure of Contents Textbook for Students

The structure of the third contents in the textbook for students of the concept of Dance Pattukduk Kumba contains material concepts briefly explain the history and meaning of dance Pattukduk Kumba; Property / Devices Dance, Costumes, and Accessories / Jewellery). While the fourth section in the textbook that is diverse Pattukduk Kumba, contains a type-type Pattukduk Kumba Variety, Variety Pattukduk Kumba, the evaluation in the form of assignments and exercises, as well as a summary of the material.

The results of the validation textbook show that: (1) textbook for students to attract and generate interest in reading for students. Textbooks according to student motivation. Motivation in this case concerning interest, appreciation, aspirations and ambitions; (2) can accommodate all learning patterns of students either individually or in groups. Materials, concepts, information, activities and variety of exercises contained in the instructional materials packaged in such a way by combining a variety of flexible learning pattern, such as individual and group assignments; and (3) the textbook for students and structured in accordance with the needs and level of competence to be achieved. In other words, the source or textbook to answer the analysis of the needs of students in the learning process and pay attention to correct each competency has been determined and will be accomplished in any learning process.

\section{Video Learning}

Video Learning is a complementary component of teaching materials as a learning device, which is designed and made as a medium of learning to train students' skills in demonstrating a wide-variety of South Sulawesi Basic Dance Pattukduk Kumbaethnic Mandar with good technique and correct motion. This instructional video is an adjustment of the course textbook Basic Dance South Sulawesi which serves as a learning tool in the lecture Basic Dance South Sulawesi. This instructional video demonstration contains Elementary learning device is expected to assist students in training, mastering, and demonstrate / demonstrate a wide-variety of dance Pattukduk Kumba so that the achievement of the course objectives can be achieved with the maximum.
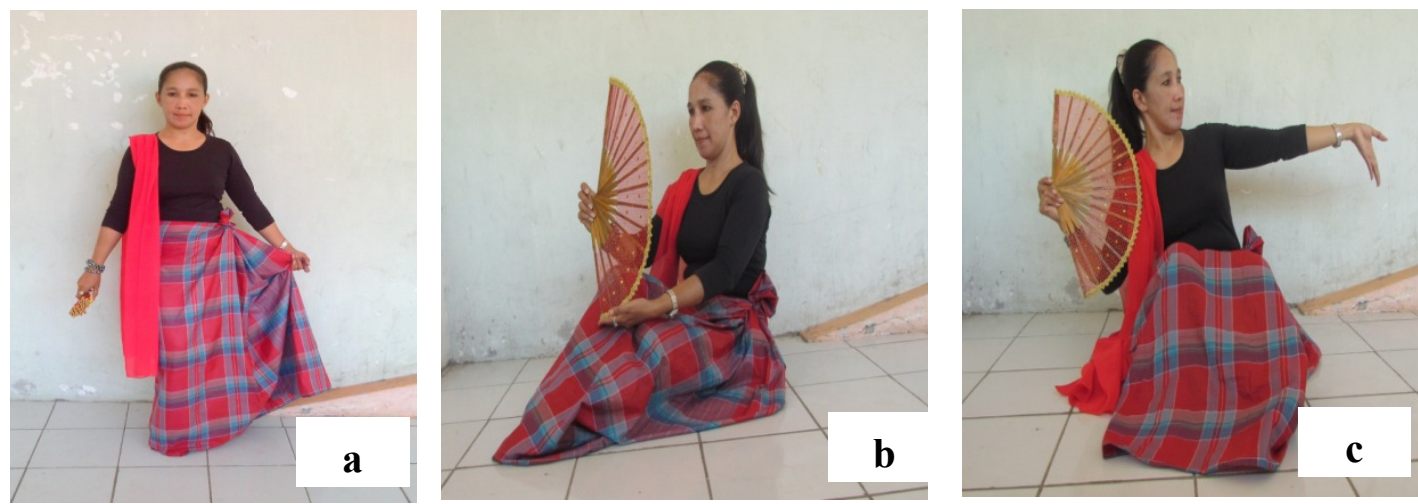

Figure 2(a). Ragam Mallappek Sipik, (b) Ragam Mioro Mijaramming, (c) Ragam Mioro Mikundur

Validation results show that the five instructional videos assessment criteria have been met, namely ease of understanding the menu, easy to use menu, the attractiveness of the display menu, the attractiveness of the public view, the attractiveness of the display wide-range of motion, and clarity of the displayed range of motion. 
Besides the description of the results of the validation of learning videos that are considered already meet namely: (1) Suitability content. 3 content/media content according to the lecture indicators to be achieved; and (2) Interactive. Students can use either independently or in groups without having to always be under the supervision and bimbigan faculty, in addition to interactively (can be repeated, is stopped (pause), accelerated, even editable.

The revised criteria, namely: (1) the suitability of the performance of dancers. At the start screen displaying two (2) dancers so that there are some movements that are less harmonious, so revised by displaying 1 person dancers only, so students are not confused anymore, because it only focuses on the motion and appearance only; and (2) the suitability of the composition of the background color and the main object (dancer). At the beginning of the video, the color of the floor and gloves kontraks dancers, giving rise to the view that is difficult to separate the two. Once revised, two more contrasting colors so that students can easily observe the motion of step dancers.

In addition to the above revision, some technical input from the validator also been followed, namely: (1) the balance display when shooting; (2) any motion that exhibited need dishot close (zoomed in) particularly those requiring special attention; (3) the displacement range of motion need to be adjusted with a steady count; (4) The camera static long shot all the circumstances suggested the movement of the hands, feet, fan, head, shoulders, and others in close-ups and Big Close Shoot (BCS); and (5) It should be noted transition device when carrying out shooting. To be more explicit depiction of movement should be combined with actors who do not use traditional clothes but only using training clothes.

Implementation of Basic learning device Dance South Sulawesi (Ethnic Mandar) are implemented on a trial class result that increased student learning outcomes after the lecture assisted by devices such as textbook for students and instructional videos. Device testing activities conducted by lecturers Basic Courses Dance South Sulawesi and as observers carried out by two colleagues who is a lecturer at the Faculty of Art and Design University of Makassar, who first described about how the implementation of the test device and the charging instrument to be filled. Implementation of the pilot performed a total of three (3) meetings and the implementation of the performance test results of picking one time meetings.

The inputs have piloted these groups, students and professors suggested that the division of the group should be determined by the lecturer, with the expectation that the group formed heterogeneity divided between men and women, schools and ethnic origin. While observers suggest that before lecturers provide learning materials, devices that will be used should be distributed to each group of at least the main textbook for students and instructional videos.

While trialing a large group learning devices Basic Dance South Sulawesi was started on 08 April to 29th April 2013. The activities carried out by the test device lecturers Basic Courses Dance South Sulawesi and as observers carried out by two colleagues who is a lecturer in the Faculty of Arts and Design University of Makassar, who first described about how the implementation of the test device and the charging instrument to be filled. Implementation of the pilot performed a total of three (3) meetings and the implementation of the performance test results of picking one time meetings.

The process is done by the end of the course provides test results to learn to know the extent of understanding and psychomotor abilities in learning implementation and effectiveness of the implementation of the learning device Basic Dance South Sulawesi (Mandar) consisting of textbook for students and instructional videos. Knowledge tests are given in the form of demonstration tests Dance Pattukduk Kumba. Analysis of the test results can be seen picking performance in the following table.

Table 1. Results of Test Analysis of Student Performance Pick

\begin{tabular}{lcccc}
\hline No & Score & Category & Frequency & Percentage \\
\hline 1 & $85-100$ & Very High & 28 & 77.78 \\
2 & $65-84$ & High & 8 & 22.22 \\
3 & $55-64$ & Moderate & 0 & 0 \\
4 & $35-44$ & Low & 0 & 0 \\
5 & $0-34$ & Very Low & 0 & 0 \\
\hline
\end{tabular}

Table 1 shows that there are 28 people or approximately $77.78 \%$ of students who obtain a very high value. 
Categorization scores high marks numbered 8 of $36 \%$ students with percentage $22.22 \%$. Meanwhile, for the category of medium, low, and very low percentage of $0 \%$. These results can clearly be said that as many as $77.78 \%$ of the students have been very understanding and be able to demonstrate Dance Pattukduk Kumba properly, and about $22.22 \%$ of students can demonstrate Dance Pattukduk Kumba well.

The results are also supported by the results of the observations made by two (2) persons who gave the explanation that Observer during learning activities Basic Dance South Sulawesi lasted most of the students can follow the course with good and serious, although there are still some students who are not too serious in university classes conducted for 3 (three) times face to face. So it is not too significant effect on learning outcomes (test results quotation performance) obtained student. In addition to knowing the student's response to the implementation of learning and teaching tools are applied in a trial class then given a questionnaire to students. The results obtained are illustrated in the following table.

Table 2. Results of response analysis of implementation of student learning and basic learning tool-based cooperative dance South Sulawesi

\begin{tabular}{llll}
\hline No & Commentary & $\begin{array}{l}\text { Student } \\
\text { Response }\end{array}$ & $\begin{array}{l}\text { Percentage } \\
(\%)\end{array}$ \\
\hline 1 & Student feelings about the lecture material & 32 & 88.89 \\
2 & Student feelings about textbooks & 30 & 83.33 \\
3 & Feelings about the student learning environment in the classroom & 33 & 91.67 \\
4 & Feelings about how faculty teach students & 31 & 86.11 \\
5 & Student opinion about the lecture material & 28 & 77.78 \\
6 & Student opinion about textbooks & 29 & 80.56 \\
7 & Opinions about student learning video & 33 & 91.67 \\
8 & Student opinion if subsequent learning using cooperative learning & 32 & 88.89 \\
& models & 26 & 72.22 \\
\hline
\end{tabular}

Table 2 shows that as much as $88.89 \%$ of the students responded positively to the learning material, as much as $83.33 \%$, the students gave a positive response to textbooks, as much as $91.67 \%$ of the students gave a positive response to how faculty teach, as much as $88.89 \%$ of the students gave a positive response if the next lesson using a model of cooperative learning, and as much as $72.22 \%$ of the students gave a positive response to the layout of the textbook. So it can be concluded that the implementation of learning koooperatif have responded positively to students. Thus, learning can take place with a conducive atmosphere.

As for the analysis of student responses to assessment textbook Basic Dance South Sulawesi obtained $88.88 \%$ of the students gave a very positive response to the presentation of the textbook. Of the six indicators of assessment for the majority of the student textbook of number 36 responded strongly agreed to the presentation of the textbook. From these data it can be concluded that the presentation of the textbook Elementary South Sulawesi acceptable Dance students well so that it can be said that the criteria set out a positive response to student learning cooperative model meets the criteria.

It is like the previous dikemukanan that the most important aspect in this study is the effectiveness, which to determine the level or degree of application of the theory, or model in a given situation. So that the effectiveness in this study is consistent according to Akker (1999), namely; effectiveness Refers to the extent that the experiences and outcomes with the intervention are consistent with the intended aims, i.e., effectiveness refers to the level of experience and the results of interventions that are consistent with the intended purpose.

\section{Conclusion}

Based on analysis of test devices in the classroom, then the outline devices that have been developed have met the criteria of effectiveness. However, the test results are still learning tools necessary to hold further revised in accordance with the advice and input of validators as well as observers and students. In order to obtain the basic learning dance cooperative model based Sulawesi valid, effective, and practical. 


\section{References}

Akker, J. V. (1999). Principles and Methods of Development Research. In J. vam den Akker, R. Branch, K. Gustafson, N. Nievenn, \& Tj. Plomp (Eds.), Design Approaches and Tools in Education and Training (pp. 1-14). Dodrecht: Kluwer Academic Publisher.

Departament National Education. (2006). Guidelines for Writing Textbooks, Textbook Explanation Quality Standard Indonesian. Jakarta: Center of Books, the Ministry of National Education.

Henich, R. (1996). Instructional Media and Technologies for Learning. New Jersey: Prentice-Hall, Inc., A Simon \& Schuster Company.

Ibrahim, M. et al. (2005). Cooperative Learning. Surabaya: Center for Science and Mathematics School of the State University of Surabaya.

Nieveen, N. (1999). Prototyping to Reach Product Quality. In J. Van den Akker, R. M. Branch, K. Gustafson, N. Nieveen, \& Tj. Plomp (Eds.), Design Approaches and Tools in Education and Training (pp. 125-135). Kluwer Academic Publishers, Dordrecht, the Nederlands. http://dx.doi.org/10.1007/978-94-011-4255-7_10

Padalia, A. (2002). Dance Pattukduk An Anthropological Study of Art About Shifting Orientation Value From Sacred to the profane in Tinambung (Unpublished thesis). Makassar: Post Graduate Program Makassar State University.

Ram, K. (2009). Turn on hit highlighting for speaking browsers Hide highlighting. The Australian Journal of Anthropology, suppl. Special Issue 12: The Politics of Dance, 11(3), 261-273.

Slagle, D. R. (2009). The Use of the Cooperative Learning Strategy STAD to Promote Academic Achievement In a High School Social Studies Class. Master of Arts in Education Program.

Slavin, R. E. (1987). Educational Psychology, Theories and Practice (4th ed.). Masschusetts: Allyn and Bacon Publishers.

Thiagarajan, S., Semmel, D. S., \& Semmel, M. (1974). Instructional Development for Training Teachers of Exceptional Children. A Sourse Book. Blomington: Central for Innovation on Teaching The Handicapped.

Trianto. (2009). Designing Innovative Progressive Learning Model: Concepts, Platform, and Implementation in Education Unit Level Curriculum. Jakarta: Kencana.

\section{Copyrights}

Copyright for this article is retained by the author(s), with first publication rights granted to the journal.

This is an open-access article distributed under the terms and conditions of the Creative Commons Attribution license (http://creativecommons.org/licenses/by/3.0/). 